\title{
A idade da memória
}

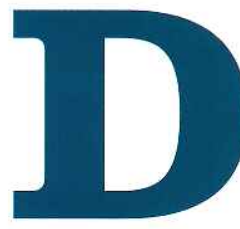

e uma perspectiva fenomenológica, ou seja, que considera o modo como cada indivíduo constrói o próprio sentido de sua existência, como interpreta os fatos e as experiências pelas quais passa, o tempo possui uma importante dimensão subjetiva. Isso significa que a sua passagem é vista de forma diferente conforme os valores e a visão de mundo de cada um. Na velhice, o tempo subjetivo que parece predominar é o passado - o velho é aquele que, pela sua própria condição, tende a olhar para trás na tentativa de manter ainda viva a memória de quem é ou foi. Neste ensaio, vários retratos da velhice são permeados pela presença insistente da memória e do passado. 


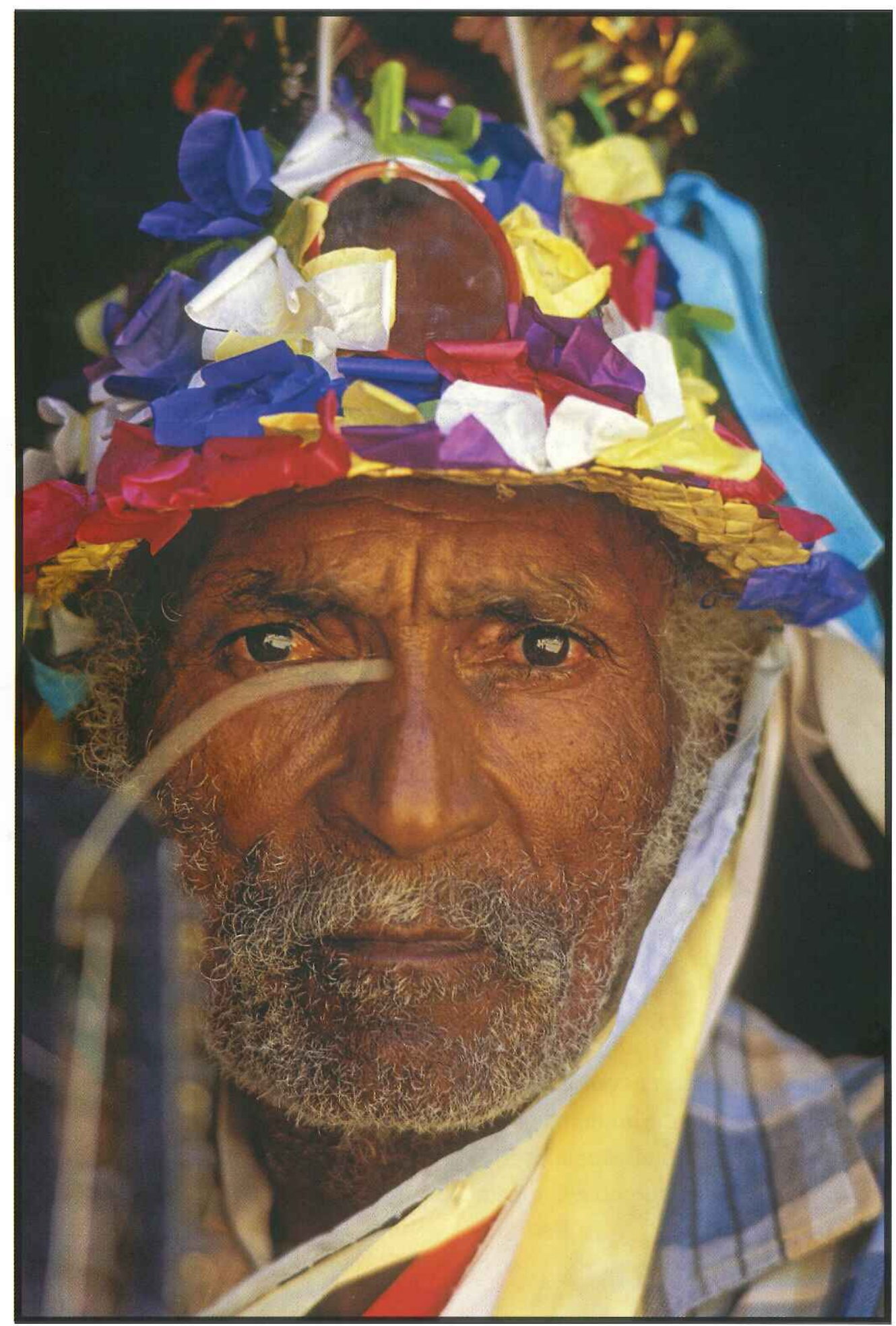

FOLIA DE REIS 


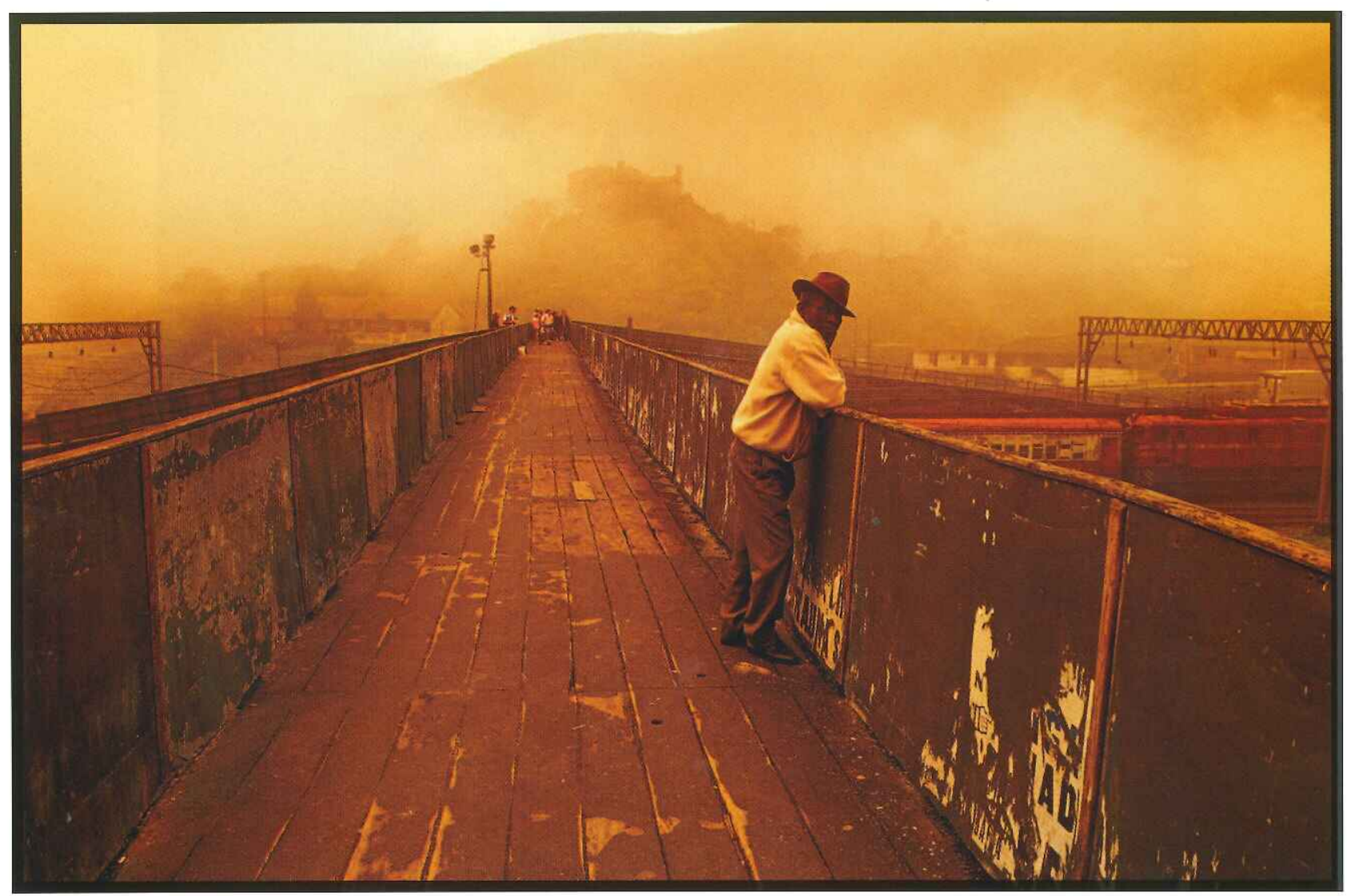

PONTE SOBRE FERROVIA

"A memória poderá ser conservação ou elaboração do passado, mesmo porque o seu lugar na vida do homem acha-se a meio caminho entre o instinto, que se repete sempre, e a inteligência, que é capaz de inovar." 


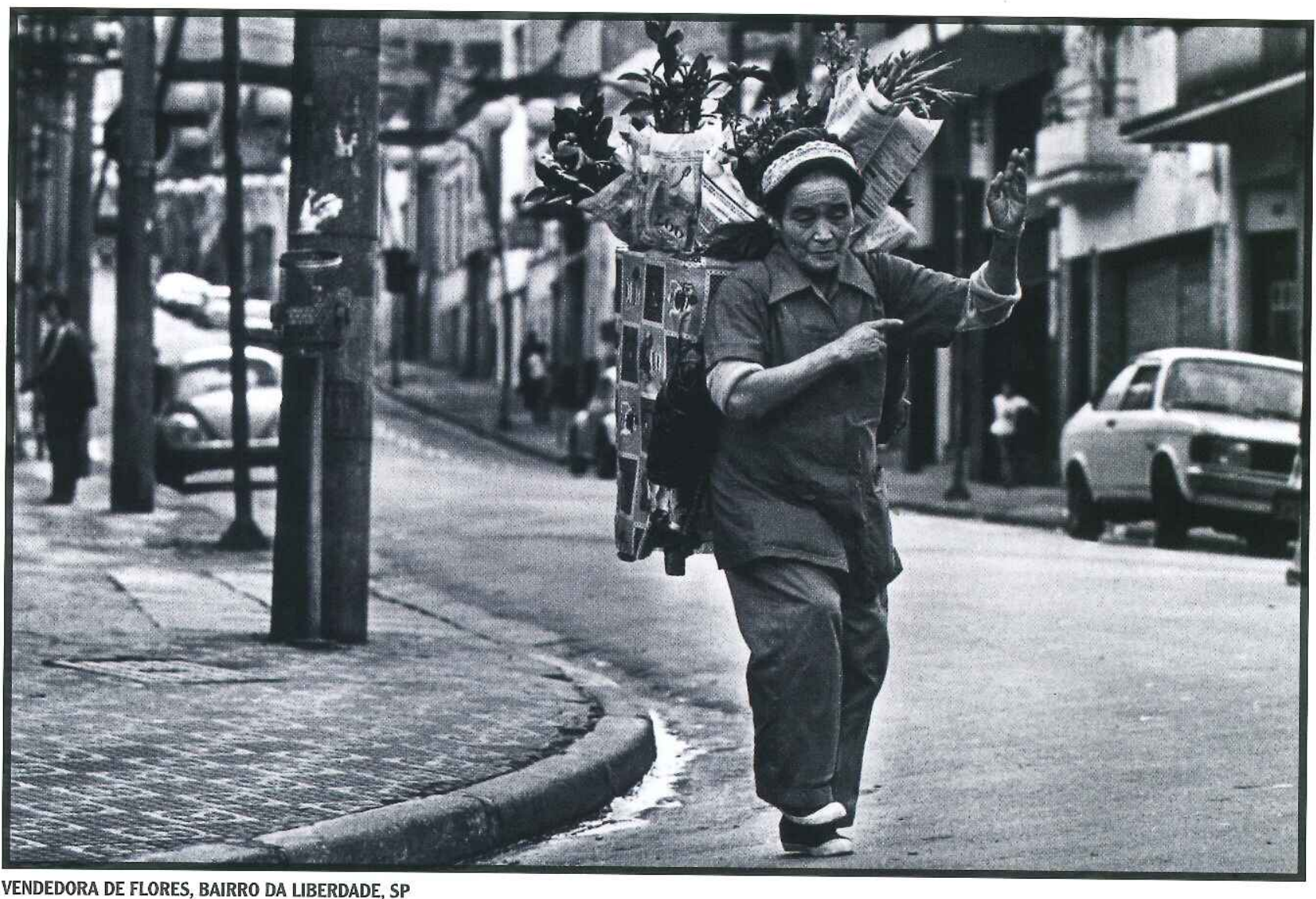

VENDEDORA DE FLORES, BAIRRO DA LIBERDADE, SP

"Ao lado da história escrita, das datas, da descrição de períodos, há correntes do passado que só desapareceram na aparência. E que podem reviver numa rua, numa sala, em certas pessoas, como ilhas efêmeras de um estilo, de uma maneira de pensar, sentir, falar, que são resquícios de outras épocas." 


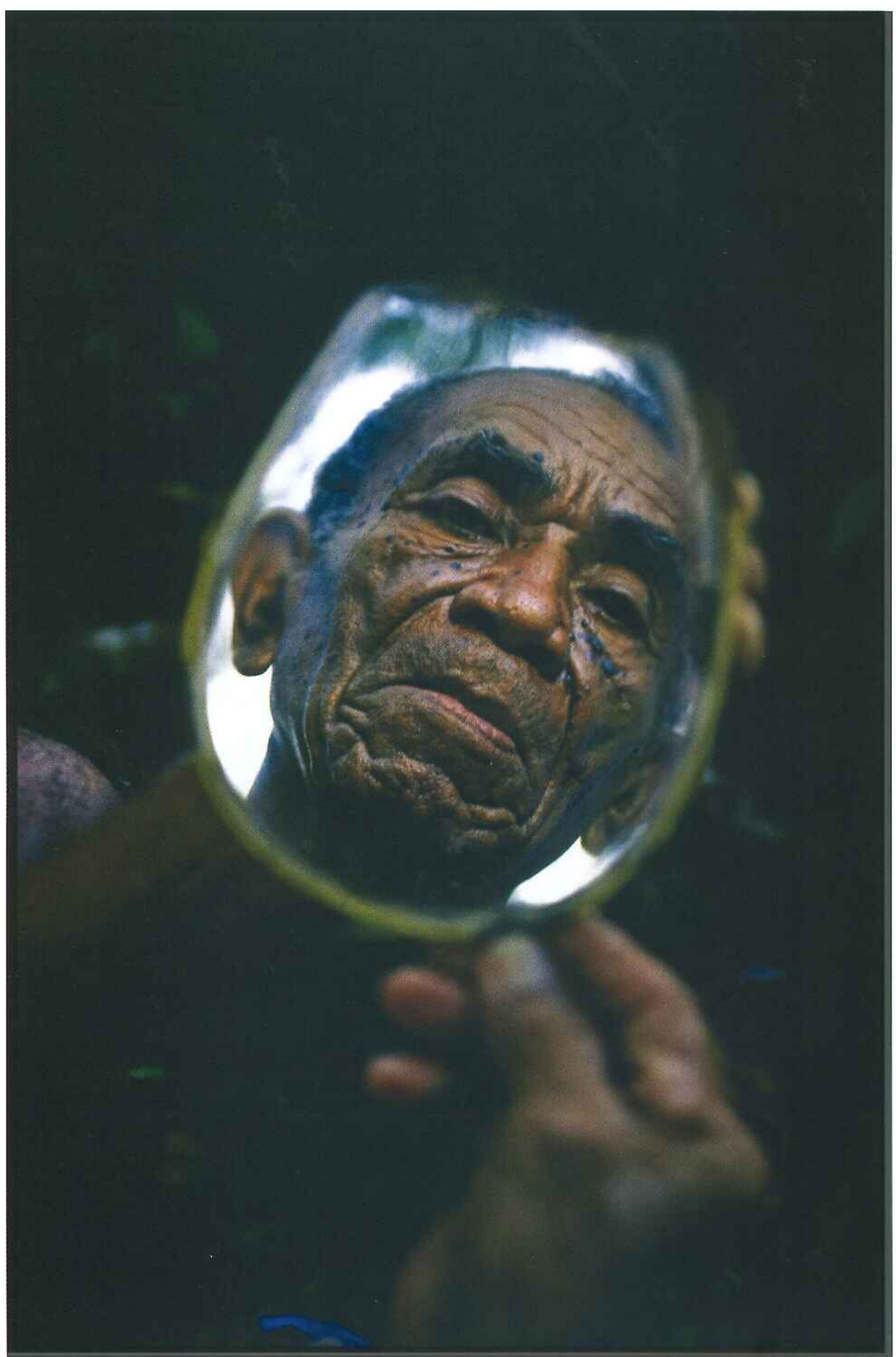

QUILOMBOLA

"Se as lembranças às vezes afloram ou emergem, quase sempre são uma tarefa, uma paciente reconstituição." 


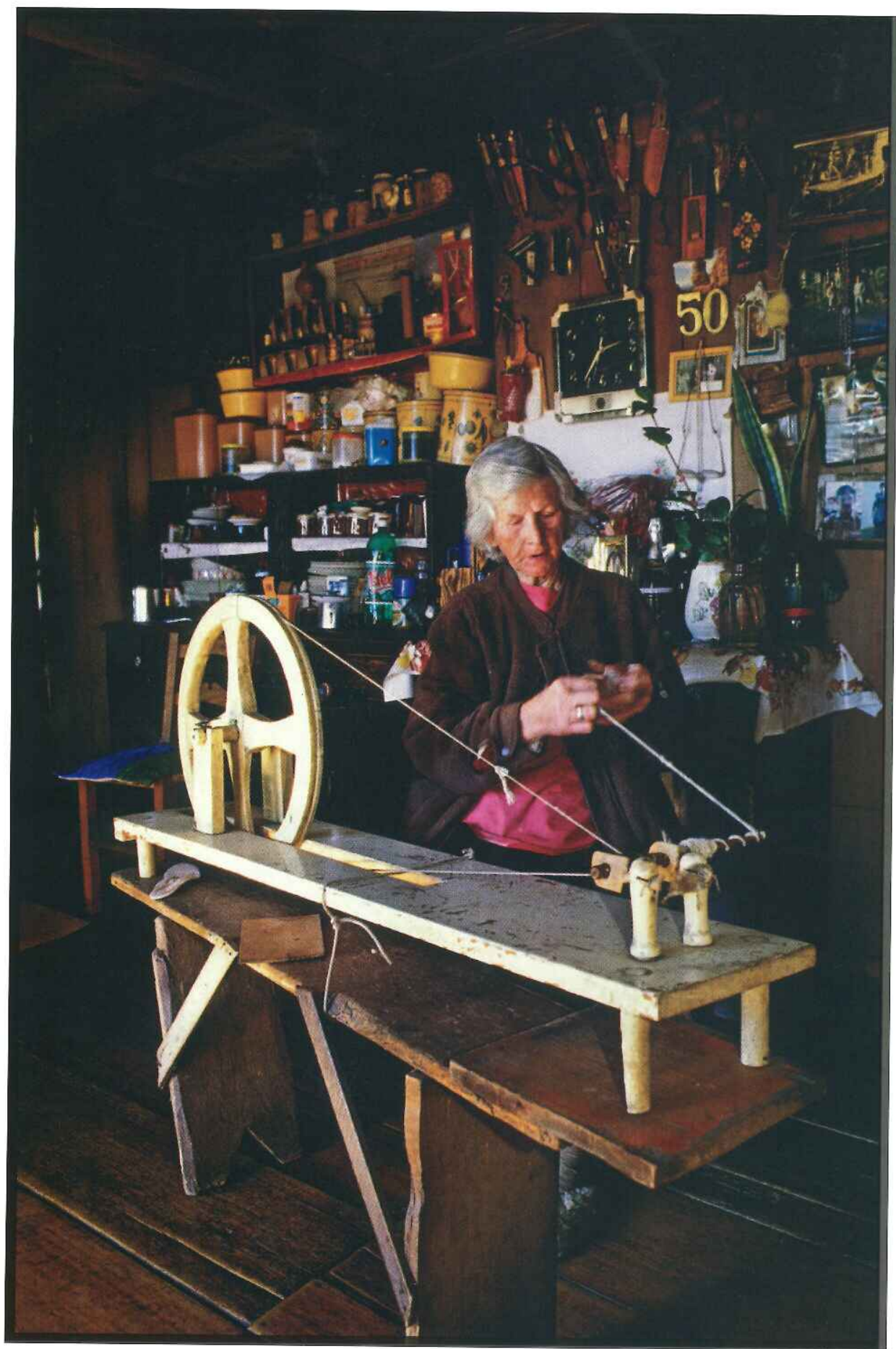

FIANDEIRA 


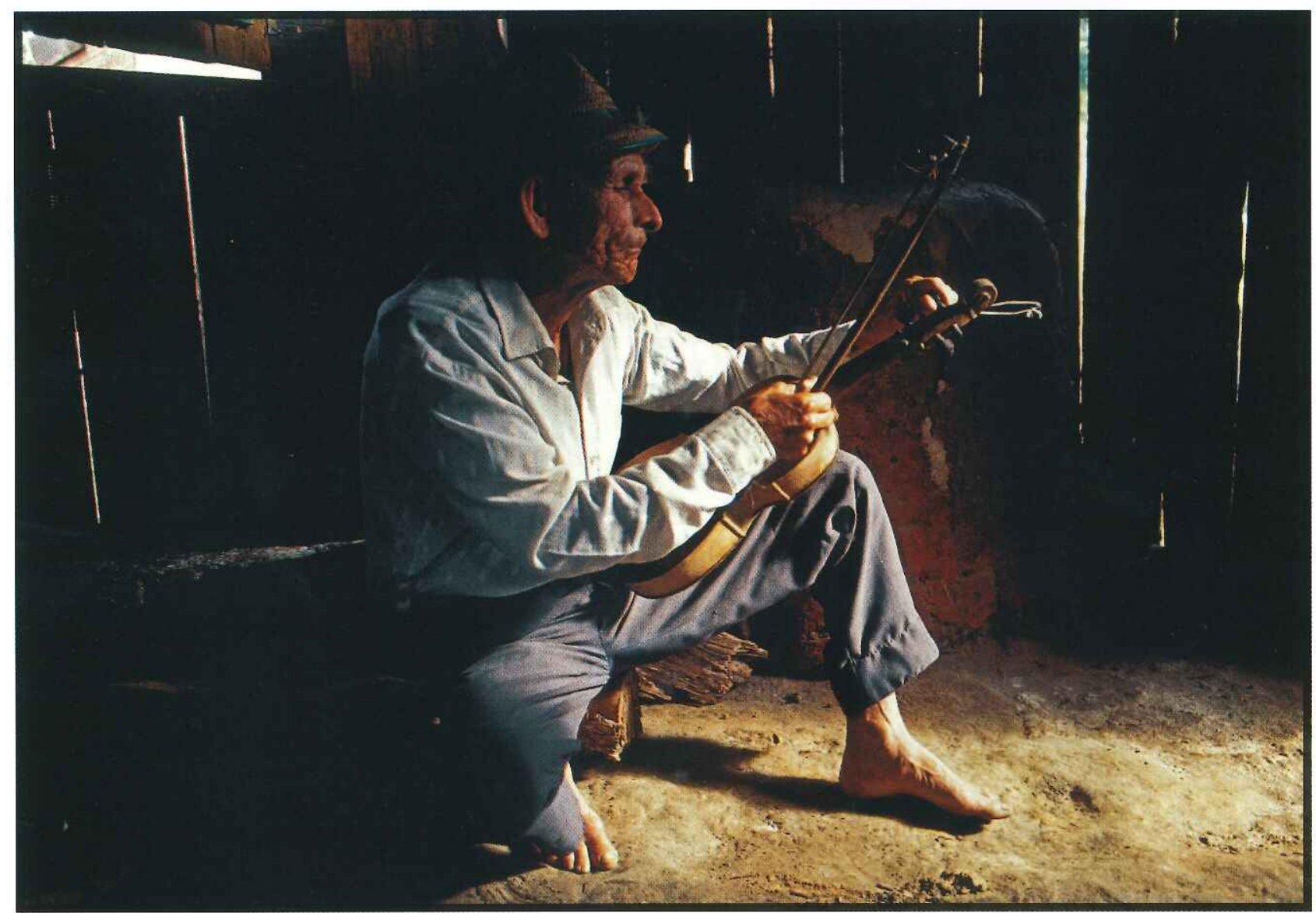

TOCADOR DE RABECA, PARQUE NACIONAL DO SUPERAGUI, PR

"Dia virá em que as pessoas que pensam como nós irão se ausentando, até que poucas, bem poucas, ficarão para testemunhar nosso estilo de vida e pensamento. Os jovens nos olharão com estranheza, curiosidade; nossos valores mais caros lhes parecerão dissonantes e eles encontrarão em nós aquele olhar desgarrado com que, às vezes, os velhos olham sem ver, buscando amparo em coisas distantes e ausentes." 


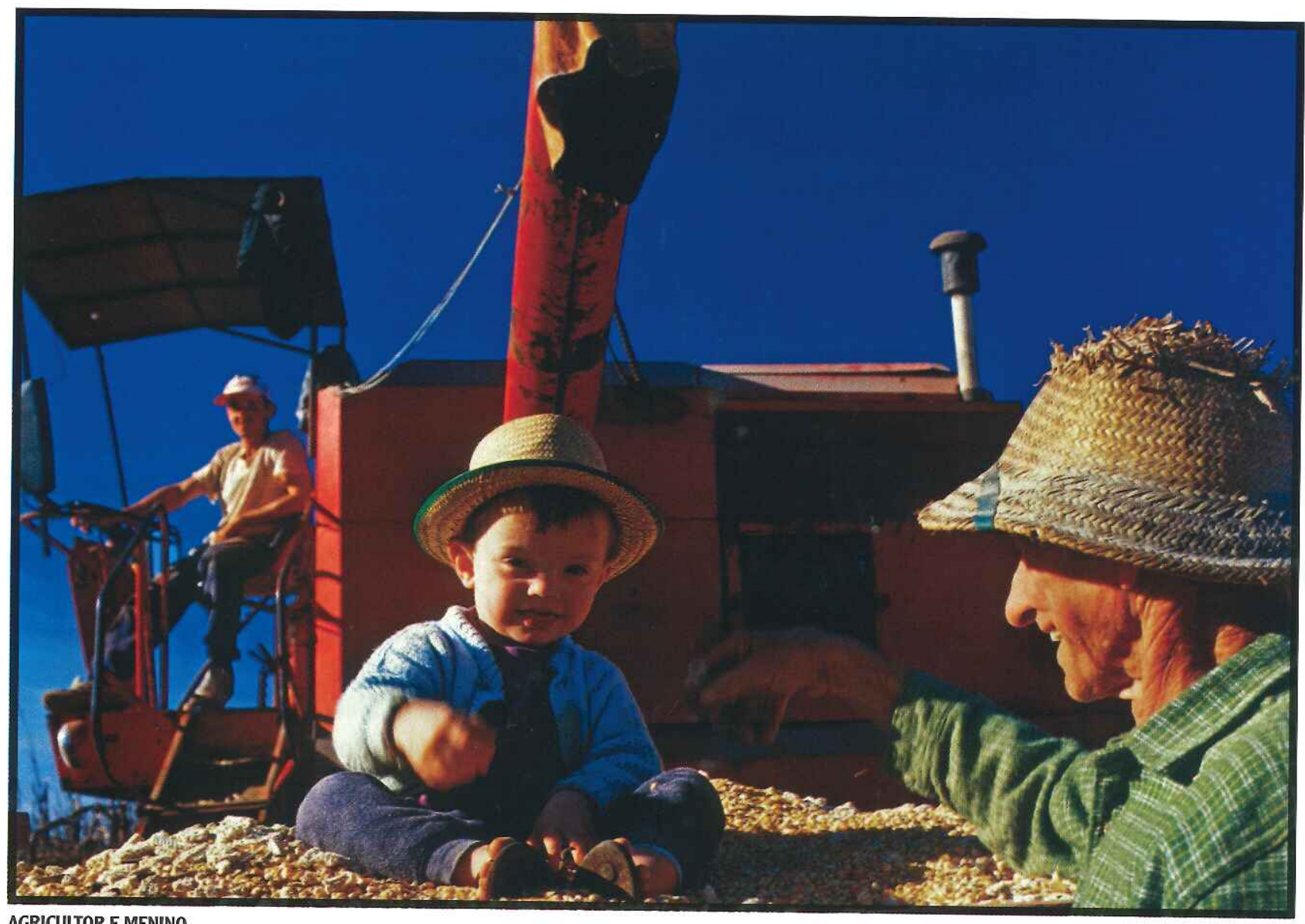

AGRICULTOR E MENINO

"A infância é larga, quase sem margens, como um chão que cede a nossos pés e nos dá a sensação de que nossos passos afundam. Difícil transpor a infância e chegar à juventude." 